\title{
Study on Maintenance Character of Motor Skills with Different Organiza- tion Levels
}

\author{
Guo-Hua Shao $^{1 *}$ and Zhi-Jian Huang ${ }^{2}$ \\ ${ }^{1}$ Institute of Physical Education, Inner Mongolia Normal University, Hohhot 010022, Inner Mongolia, China; ${ }^{2}$ College \\ of Health Science, Wuhan Sports University, Wuhan 430079, Hubei, China
}

\begin{abstract}
The research field of motor skills has become wider and wider. This paper, based on different organization levels; took 107 students from Inner Mongolia Normal University as research subjects for two events, Wushu and swimming. The research result shows that the motor skills maintenance curve for Wushu comes in " $\mathrm{M}$ " shape with its relatively low organization level, while the curve for swimming is in "W" shape, for its relatively high organization level. And as to the acquisition of motor skills of different organization levels, the group with a high learning level maintains much better than group with a medium or a low learning level, and the discrepancy is quite apparent.
\end{abstract}

Keywords: Maintenance, motor skill, organization level.

\section{RESEARCH PURPOSE}

The main purpose of this research is to select two events, Wushu and swimming, as samples of a high organization level and a low organization level, and based on the actual situation as well as former researches by other scientists to make this research with a more practical significance, avoiding affecting the teaching plan and process, this research only tested the target sports events again and described the related maintenance curves for a further conclusion, aiming at finding the maintenance under different organization levels, so as to provide guidance for the teaching of motor skills of different organization levels.

\section{RESEARCH METHODS}

\subsection{Mathematical Statistics Method}

SPSS15.0 was used for statistic analysis of the experiment data.

\subsection{Experimentation}

\subsubsection{Experimental Subjects and Methods}

107 students from non-sports major in Inner Mongolia Normal University were taken as the experimental subjects and divided into two experimental classes, one for the teaching of Wushu Routine, and the other for swimming, and the retention rate of motor skills was shown by the ratio of retention test and first test. It studied the maintenance rate of motor skills of different organization levels in current physical education by randomly dividing each experimental class into five sub-groups without affecting the 36 hours teaching plan. Each sub-group was allocated to a retention test at the time interval 1,2,6,15,31 days, and then the result of retention rate could be got accordingly, finally a retention curve chart could be obtained [1].

\subsubsection{Experimental Procedures}

The code of points of Wushu Routine and swimming were strictly marked with a set standard with at least eight Level B national referees to mark for each student, one of which was the teacher of this course. All the evaluation process was fair, impartial and open. The first test of Wushu Routine and swimming were arranged at the $35^{\text {th }}$ and $36^{\text {th }}$ class hour, and in order to ensure the authenticity of the data, we didn't inform the students of the retention test so as to avoid lots of practice. All students were given 20 minutes for preparation before both the first and the retention tests, then points should be marked according to the standard after each student finished the whole set of motor skills. And the rules and standards of the retention test was the same as those of the first test. Marks from each referee were recorded and collected for further analysis, and all the marks were examined by the kendall coefficient of concordance, with the results of $\mathrm{W}_{1}=0.93 \quad \mathrm{~W}_{2}=0.95$ [2].

\section{RESEARCH RESULTS}

We collected and analyzed the data after the first and retention tests for Wushu Routine of a low organization level. The following is the curve chart for maintenance rate for it.

From the Curve of the maintenance rate of Wushu (Chart 1), we can see that after the first test, there existed a rising rate in the retention test after the first day, then a drop on the second days; yet, another rising up to the rate of the first test on the sixth day compared with the second day; while on the fifteenth day and the thirty-first day, an obvious decline compared with the first three retention tests. The whole curve appeared in "M" shape [3]. 


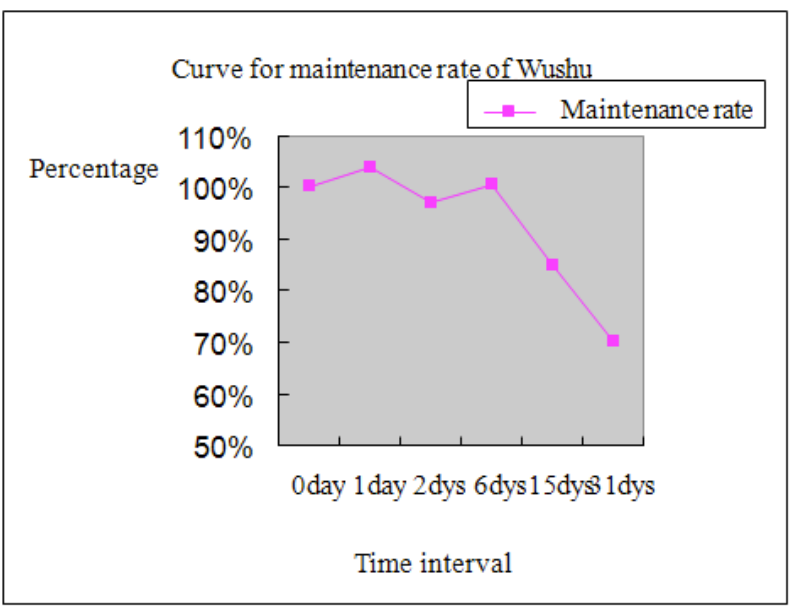

Chart 1. Curve of the maintenance rate of Wushu.

Then we divided the students' learning performance into three groups (high, medium and low level). After calculation, the group with high learning level showed $X_{1} \geq 84.0$, low learning level $\mathrm{X}_{2} \leq 73.9$, and medium learning level $84.0<\mathrm{X}<73.9$. The statistical result is shown in Table 1. There were obvious differences between learning performance and learning level, learning performance and time interval.

The Analysis of variance of multi-factors in Wushu Routine (Table 2) suggested that there existed an apparent difference in learning level and time intervals.
From Multi-level comparison learning level in Wushu Routine (Table 3), there was a clear difference between group with a medium learning level and that with a low learning level, and the similar difference also existed between group with a high learning level and that with a low learning level, while no such difference was found between group with a high learning level and that with a medium learning level [4].

Judging from Multi-level comparison of time intervals in Wushu Routine (Table 4), there was a clear difference between the thirty-first day and the other days, while no differences between other time intervals.

We collected and analyzed the data after the first and retention tests for swimming of a high organization level, and the curve chart for maintenance rate is as follows.

In Chart 2, the curve did not fluctuate much compared with Chart 1, yet it was enough for the conclusion that the motor skills of swimming as a sports event with a high organization level was easier to maintain than those of Wushu Routine with a low organization level. From Chart 2, we can see that after the first test, there existed a drop rate in the retention test after the first day, yet a rising rate on the second days; and, another drop on the sixth day compared with the second day; while on the fifteenth day and the thirty-first day, there was a general rising rate compared with the previous retention tests, yet with a close rate as the first test with almost no change in maintenance rate. The whole curve came in adverse " $\mathrm{M}$ " shape, like the "W" shape. However,

Table 1. Statistics for learning performance, learning levels, and time intervals of Wushu routine learning.

\begin{tabular}{|c|c|c|c|}
\hline Pearson Correlation & Result & Level & Time Interval \\
\hline \hline Learning performance & & $-.556^{* *}$ & $-.57^{* *}$ \\
\hline Learning level & $-.556^{* *}$ & & -.001 \\
\hline Time interval & $-.57^{* *}$ & -.001 & \\
\hline
\end{tabular}

Note: *means $\mathrm{p}<.05, * *$ means $\mathrm{p}<.01$

Table 2. Analysis of variance for multi-factors in Wushu routine.

\begin{tabular}{|c|c|c|c|}
\hline Differences & Mean square & Values of F & Sig. \\
\hline \hline Learning level & 1843.57 & 19.65 & .000 \\
\hline Time interval & 973.69 & 10.38 & .000 \\
\hline Learning level*Time interval & 75.40 & .804 & .602 \\
\hline
\end{tabular}

Table 3. Multi-level comparison learning level in Wushu routine.

\begin{tabular}{|c|c|c|c|}
\hline Learning Level & Low & Medium & High \\
\hline \hline Low & & $-19.89^{*}$ & $-23.29^{*}$ \\
\hline Medium & $19.89^{*}$ & & -3.40 \\
\hline High & $23.29^{*}$ & 3.40 & \\
\hline
\end{tabular}

Note:*means $\mathrm{p}<.05,{ }^{* *}$ means $\mathrm{p}<.01$ 
Table 4. Multi-level comparison of time intervals in Wushu routine.

\begin{tabular}{|c|c|c|c|c|c|}
\hline Time Interval & $\mathbf{1}$ day & $\mathbf{2}$ days & $\mathbf{6}$ days & $\mathbf{1 5}$ days & 7.59 \\
\hline \hline 1 day & & 5.56 & 2.39 & 2.03 & $26.92^{*}$ \\
\hline 2 days & -5.56 & & -3.16 & 5.20 & $24.36^{*}$ \\
\hline 6 days & -2.39 & 3.16 & -5.20 & $19.32^{*}$ \\
\hline 15 days & -7.59 & -2.03 & $-24.53^{*}$ & $-19.32^{*}$ & \\
\hline 31 days & $-26.92^{*}$ & $-21.36^{*}$ & & \\
\hline
\end{tabular}

Note: *means $\mathrm{p}<.05$

Table 5. Analysis of variance for multi-factors in swimming event.

\begin{tabular}{|c|c|c|c|c|c|}
\hline Different Items & $\begin{array}{c}\text { Sum of Squares of } \\
\text { Deviations }\end{array}$ & Degree of Freedom & Mean Square & Values of F & Sig. \\
\hline \hline Learning level & 770.767 & 2 & 385.384 & 30.472 & .000 \\
\hline Time interval & 199.621 & 4 & 49.905 & 3.946 & .061 \\
\hline $\begin{array}{c}\text { Learning level*time } \\
\text { interval }\end{array}$ & 374.638 & 8 & 46.830 & .64 \\
\hline
\end{tabular}

Table 6 Multi-level comparison of learning level in swimming event.

\begin{tabular}{|c|c|c|c|}
\hline Learning Level & Low & Medium & High \\
\hline \hline Low & & $-6.24^{*}$ & $-8.78^{*}$ \\
\hline Medium & $6.24^{*}$ & & -2.54 \\
\hline High & $8.78^{*}$ & 2.54 & \\
\hline
\end{tabular}

Note: *means $\mathrm{p}<.05$

the general fluctuation of the whole curve was not so fierce as compared with that of Wushu Routine; that is to say, swimming as a sport with a high organization level, had a relatively high maintenance rate.

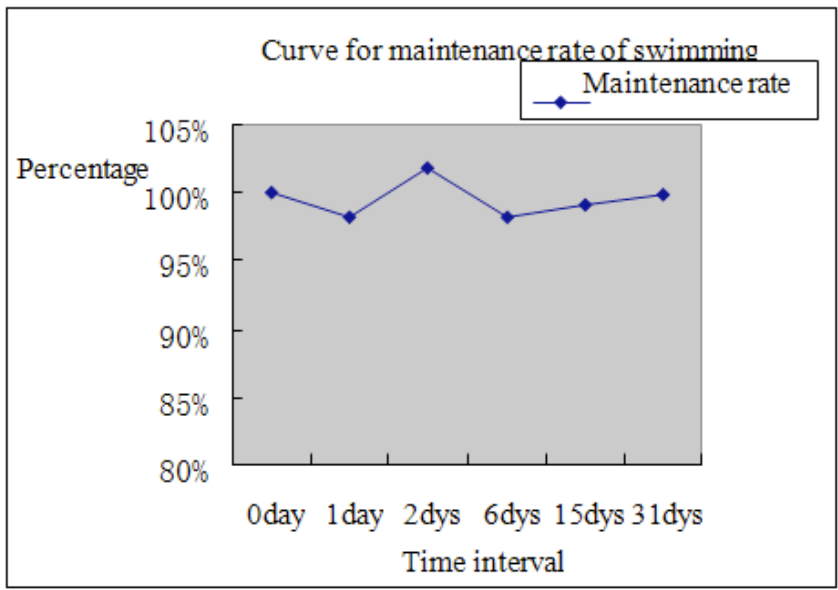

Chart 2. Curve for the maintenance rate of swimming event.

Then we divided the students' learning performance of swimming into three groups (high, medium and low level).
After calculation, the group with a high learning level showed $X_{1} \geq 87.7$, low learning level $X_{2} \leq 81.8$, and medium learning level $81.8<\mathrm{X}<87.7$. And result in Table 5 indicated that there was no obvious difference between each time interval, which also suggested that swimming with a high organization level, had a relatively high maintenance rate, and forgot more slowly compared with that of Wushu Routine with a low organization level.

From the result of Multi-level comparison of learning level in swimming event (Table 6), there was a significant difference between group with a medium learning level and that with a low learning level, and the similar great difference also existed between group with a high learning level and that with a low learning level, while no such difference was found between group with a high learning level and that with a medium learning level. This result was the same as that of Wushu Routine, suggesting that as to the acquisition of motor skills, the group with a high learning level had a higher maintenance rate than that with a low learning level.

From Chart 1 and Chart 2, the maintenance rate in either event had a period of over rating, as the acquisition of motor skills was much better than the first tests. There could be various reasons to explain such phenomenon, maybe there was a protective inhibition in the nerves of the brains of the 
students' as well as a negative stimulation effect in the brains after the very short period of learning the new motor skills; and some scholars concluded it as the complexity and joy of sports activities, with the reactive information of the muscle itself coming to the brain after doing the sports, it actually equaled to a further learning and a strengthening of the memory, which resulted in such phenomenon.

\section{CONCLUSION}

(1) The curve generally appeared "M" shape in the process of motor skills in Wushu, suggesting that organization with a low level would maintain a shorter time and forget quickly; while the curve came in "W" shape in the motor skills maintenance process of swimming, indicating that organization with a high organization level would maintain a longer time and forget slowly.

(2) As to the acquisition of motor skills of different organization levels, the group with a high learning level maintained much better than group with a medium or a low learning level, and the discrepancy was quite apparent.

(3) There existed a "memory recovery" in either low or high organization level. Thus, it leaves a further discussion for when is the best time for revision of motor skills, which means the time point for revision should be well chosen according to the different maintenance rate of different organization levels, so as to achieve a better learning and acquisition of motor skills.

\section{CONFLICT OF INTEREST}

The authors confirm that this article content has no conflict of interest.

\section{ACKNOWLEDGEMENTS}

Declared none.

\section{REFERENCES}

[1] R.A. Magill, Motor Learning: Concepts and Application, New York: McGraw-Hill, 2001, pp. 126-149.

[2] R.A. Schmidt, Motor Control and Learning: A Behavioral Emphasis, $3^{\text {rd }}$ ed, Champaign, IL: Human Kinetics, 1999.

[3] R.A. Magill, and Z. Zhang Motor Learning and Control, Beijing: China Light Industry Press, 2006.

[4] G.-H. Shao, G. Meng, and Z.-Z. Li, "Study on the forgetting process of motor skill in sport events of throwing and primary fencing", Journal of Guangzhou Sport University, vol. 30, no. 1, pp. 86-88, 2010.

\footnotetext{
Received: June 10, 2015

Revised: July 29, 2015

Accepted: August 15, 2015

(C) Shao and Huang; Licensee Bentham Open.

This is an open access article licensed under the terms of the (https://creativecommons.org/licenses/by/4.0/legalcode), which permits unrestricted, noncommercial use, distribution and reproduction in any medium, provided the work is properly cited.
} 